\title{
How to Think about the Debate over the Reality of Beliefs
}

\section{Krzysztof Poslajko ${ }^{1}$ (D)}

Accepted: 11 April 2021 / Published online: 21 April 2021

(C) The Author(s) 2021

\begin{abstract}
The aim of this paper is to propose a new conceptualization of the distinction between realism and anti-realism about beliefs that is based on the division between natural and non-natural properties, as defined by Lewis. It will be argued that although the traditional form of anti-realism about beliefs, namely eliminative materialism, has failed (as it led to unacceptable consequences), there is a possibility to reformulate the division in question. The background assumption of the proposal is the framework of deflationism about truth and existence: it will be assumed that beliefs can be said to exist and their attributions can said to be true. The aim is to show that even when we buy into such assumptions we can meaningfully distinguish between the realist and anti-realist approach to belief. According to the proposal, the paradigmatic anti-realist view on beliefs should be seen as a conjunction of three claims: that belief attributions do not track objective similarities, that beliefs are not causally active, and that there is no viable way of naturalizing content. It will be shown that seeing the debate in the proposed way has important advantages as it allows the issue of belief realism to be made non-trivial and tractable, and it introduces theoretical unity into contemporary metaphysics of beliefs.
\end{abstract}

\section{Introduction}

The problem of whether beliefs are real was one of the most hotly discussed issues in the metaphysics of mind in the second half of the twentieth century. As it was characterized by Dennett (1991), the three main positions in the debate were: strong realism, represented primarily by Fodor (1985), moderate realism championed by Davidson (1970) and Dennett himself, and eliminativism proposed by Churchland (1981). Strong realists considered beliefs to be real in a literal sense: for them beliefs are concrete states realized in the brain (although they might be multiply realized on the

Krzysztof Poslajko

krzysztof.poslajko@uj.edu.pl

1 Department of Philosophy, Jagiellonian Center for Law, Language and Philosophy, Jagiellonian University, Grodzka 52, Krakow 31-044, Poland 
neuronal level), which are at the same time genuine causes of behavior and bearers of semantic properties. Moderate realists want to retain the idea that people have beliefs but without committing themselves to what they see as the problematic presuppositions of strong realism. Eliminativists, on their part, deny the reality of beliefs altogether: for them beliefs simply do not exist, and all first-order statements in which we attribute them are simply false.

This debate has become less pronounced nowadays. Although there are still interesting developments in the metaphysics of beliefs (Schwitzgebel's (2002) defense of neo-behaviorism might be a prominent example here), the issue of the reality of beliefs seems not of primary interest in contemporary philosophy of mind. Two hypotheses might be put forward to explain this phenomenon. First, the issue of the reality of beliefs has been to an extent replaced by the issue of the reality of the representational posits of contemporary cognitive science (this has been noted by Rupert (2018), for example). Second, the negative view on the reality of beliefs, namely eliminativism, has been widely regarded as unworkable (this is conceded even by Churchland (2007)). As the threat of anti-realism disappeared, the debate appeared to be solved. Realism (of different varieties) has become a sort of default position which does not need to be proved.

My aim here is to try to somewhat undermine this consensus by showing that the debate about the reality of beliefs can be phrased in different terms than it was originally presented. In this way, I plan to achieve three important philosophical aims. First, the proposed conceptualization of the debate will make it non-trivial: I aim to define the anti-realist position in such a way as to make this view immune from the popular charges of internal inconsistency. Second, my definition will introduce some sort of theoretical unity into various debates in the metaphysics of beliefs. Third, it should make the debate about the reality of beliefs tractable, at least to an extent: it should provide us with some ways of deciding between realism and a reasonable form of anti-realism.

It is hard to provide an exact definition of the concept of belief. Usually, this category is introduced in the philosophical literature by way of examples: Galileo believed that the sun was not rotating around the earth, whilst I believe that all movement is relative. Such examples are used to motivate some sort of relational analysis of belief: beliefs are most often thought to be relational states in which a subject who harbors a given belief is somehow connected to certain propositional content.

In my opinion, beliefs are of central importance to analytic philosophy, as the idea of beliefs is the idea of states which combine two crucial features (see e.g. Zawidzki 2013 for such a characterization). First they play an important role in the explanation of intentional actions in virtue of the fact that they are an element of so-called practical syllogism. As a consequence, beliefs are usually taken to be causally active. Second, they are bearers of semantic properties: beliefs are usually considered to be those mental states which possess truth-conditions.

In this way, beliefs might be treated as being states which, speaking somewhat metaphorically, bridge the sphere of causes with the realm of reasons. Beliefs, as it seems, enter both causal and logical relations. As bearers of semantic propositional content, beliefs can be treated as having logical properties: they entail each other, they can be inconsistent with each other, etc. Also, they are treated as being real causes of 
behavior. Consequently, resolution of the issue of belief-realism is vital to philosophy because the presupposition that beliefs are real seems to be implicit in many parts of philosophical theorizing. The idea that the notion of belief has a certain important explanatory role to play in many areas of philosophy seems to enjoy widespread, albeit tacit, approval: in philosophy of language, philosophy of action, and many other philosophical sub-disciplines, it is customary to build philosophical theories which treat belief as an explanatory notion. However, such an explanatory practice relies implicitly on belief-realism: we might justifiably treat beliefs as playing important roles in explanation only if we treat them as real in some relevant sense.

The plan of the paper is as follows. First, I will introduce eliminativism and some of the reasons that this way of articulating the anti-realist intuition about beliefs can be considered a failure; then I will discuss the consequences of this failure. Second, I will introduce my proposal of conceptualizing the distinction between realism and antirealism about beliefs in terms of Lewis's contrast between natural and non-natural properties; in order to make this division clear, I will characterize the paradigmatic versions of realism and anti-realism. Thirdly, I will indicate some important theoretical advantages of my proposal. Finally, I will highlight some reasons which might be seen as prima facie supporting the anti-realist option.

\section{Eliminative Materialism}

Eliminative materialism was presented in its classical form by Churchland (1981), although there were important predecessors of this view, for example Quine (1960). Churchland's version of the eliminativist argument goes as follows: beliefs are theoretical posits of the proto-theory of folk psychology. Folk psychology is a failed theory as it does not meet the standards of a good theory: it does not progress, it cannot be made consistent with other well-developed theories, and it cannot explain many vital phenomena. Thus, folk psychology should be seen as false, and its posits should be treated as non-existent. Churchland also famously postulated that in some unspecified point in the future we will be able to do away with attributing beliefs to ourselves and others: folk psychology might eventually be replaced by mature neuroscience.

To my mind, the most important aspect of eliminativism lies not in its dubious futuristic predictions/postulates but in its negative ontological claim that beliefs do not exist (this ontological aspect of eliminativism is treated as central by e.g. Daly 2013). In this way, the eliminativist claim is the most straightforward and radical form of denying the reality of beliefs. Eliminativists see beliefs as not real and express this conviction ontologically by claiming that there are no such states as beliefs.

Unsurprisingly, the eliminativist proposal faced strong opposition. There were two main ways of criticizing the position in question. The first was by trying to show that the premises of the eliminativist arguments are unjustified: some (see Ravenscroft 2016 for an overview) claimed that folk psychology cannot be really seen as a theory; others argued that it is in fact a successful theory (see e.g. Fodor 1987), and yet some others pointed out that the eliminativists' argument relied on the unfounded presupposition that the descriptive theory of reference is correct (see e.g. Mallon et al. 2009). The other and perhaps the most philosophically intriguing way of resisting eliminativism was by way of claiming that no matter what the arguments for eliminativism are, we simply 
cannot accept the eliminativistic conclusion: either because it is inconsistent or because it results in an unacceptable conflict with common-sense.

Eliminative materialism, as it is defined above, is a form of error-theory about the folk-psychological domain (with a special emphasis on beliefs). Thus, its two main claims are that beliefs do not exist and that, as a consequence, all elementary first-order sentences in which we attribute beliefs must be deemed false. This second consequence might be considered to be the core of belief-irrealism.

Some philosophers claim that such irrealism about beliefs is, in principle, inconsistent: according to this line of thought, in order to express the eliminativist claim one must presuppose that one has beliefs (this is the famous cognitive suicide argument that was proposed by Baker (1987) and developed by Boghossian (1990)). Eliminativism is thus said to be a self-undermining position as its formulation requires adopting a claim (that one has beliefs) that is directly contradicted by the theory.

There are numerous issues with this argument, and the issue of whether eliminativism is truly an internally inconsistent position depends on many substantial philosophical assumptions; it might be the case that the accusation of inconsistency can be resisted by way of making fine technical philosophical distinctions. But these observations do not change the general impression that something is amiss with eliminativism: there is some sort of general consensus that this position cannot work and that we cannot coherently accept this position. This might be due to the highly counter-intuitive character of eliminative materialism, which brings us to the second argument against the eliminativist conclusion, namely that it is incompatible with common-sense.

This argument was presented in the most developed form by proponents of so-called common-sense functionalism (see Jackson and Pettit 1990, 1993). According to this view, the claim that beliefs exist might be justified by pointing out that the conditions specified by the common-sense platitudes which determine our ordinary concept of belief are fulfilled. In this way we might, according to common-sense functionalists, rest assured that people actually possess beliefs and other attitudes, no matter what skeptical arguments the eliminativist could produce. Moreover, the conviction that people have beliefs is independent of future developments in neuroscience: we do not need assurance from any basic science to safely make this claim. Nothing more is needed to defend the thesis that beliefs exist than the observation that the conditions specified by the platitudes of folk-psychological theory are fulfilled by actual humans.

I think that this is quite a powerful way of arguing against eliminativism as it shows that the epistemic warrant in accepting the truth of folk-psychological attributions is much stronger than eliminativists would be willing to admit. In this way, the thesis that people do possess beliefs turns out to be a sort of Moorean truth, i.e. a claim that is highly justified by our pre-theoretical commitments and which cannot be disproved by arcane philosophical arguments.

A characteristic feature of these arguments against eliminative materialism is that they do not provide us with a positive reason to think that people really do have internal, causally active states which are bearers of semantic, propositional content. Rather, they show that the eliminativist claim that "there are no beliefs" is unacceptable for some reason or other. As a result, the debate about the reality of beliefs has reached the point at which one of the main positions is deemed unworkable from the start. Thus, the debate might be seen as having become, as it were, trivialized: as the negative claim 
about the reality of beliefs is largely seen as being unworkable, no pressure is felt to provide positive reasons to think that beliefs are real.

In my opinion, what caused the demise of traditionally conceived eliminativism was the way in which its proponents framed their position. In the general spirit of broadly conceived Quinean meta-philosophy, in which the philosophical issues of reality are summarized in the question of "what there is" (see Quine 1948), the question of the reality of beliefs is presented as the question of whether beliefs exist (see e.g. Stich 1983, esp. pp. 221-222, for a more detailed analysis of the relation between eliminativism and Quinean methodology of philosophy).

To sum up, the eliminativists framed their thesis as a negative ontological claim about beliefs. This led to irrealism about beliefs, i.e. the claim that statements that attribute beliefs can never be true. However, this claim strikes most philosophers as being incredible to the point of being somehow incoherent. Consequently, eliminative materialism was commonly rejected.

This observation, however, does not have to lead us to think that any sort of metaphysical scruples regarding the reality of beliefs must be considered misguided. The other conclusion we might get from this appraisal of the situation is that antirealists should try to express their basic intuition (namely that beliefs are not real) in some other way than in terms of existence and truth. In what follows I will try outline such a proposal.

\section{The Alternative Proposal}

In my opinion the best way to conceptualize the anti-realist view about beliefs is by adopting a view that combines two major elements. The first is the general deflationary outlook on existence. The second is the idea that belief-properties are not natural in Lewis's sense of naturalness. Let me discuss these ideas in turn.

According to meta-ontological deflationism, whose main proponents are Schiffer (1996) and Thomasson (2015), existence questions should be considered easy. According to Schiffer, many questions about existence which were traditionally deemed controversial can be given a positive answer by means of what he calls "pleonastic transformations". Consider the question of whether numbers exist. On Schiffer's approach we might easily establish a positive answer to this question by means of simple reasoning of the following sort: Let us take an uncontroversial empirical statement, like the claim "Mars has two moons". From this we can infer the statement "The number of Mars' moons is two", and from this second statement we might infer that there exists at least one number (number two); therefore, numbers exist.

On Thomasson's “easy ontology" approach (Thomasson 2015), there are two steps that are needed to establish the fact that certain Ks exist. First, we need to establish, by means of conceptual analysis, what the application criteria of the term " $\mathrm{K}$ " are. Second, we need to empirically check whether these application criteria are met. So, for example the question of whether tables exist should be answered by first establishing the criteria of applying the term "table", and, second, by checking by means of trivial empirical inquiry whether said criteria are met.

The deflationary approach to existence has two important features. First, it allows many questions about existence to be answered in the positive, which has traditionally 
been conceived as problematic: for example, on the deflationary approach we might establish that there are numbers, properties, material objects and so on. Secondly, deflationists reject the idea that existence questions are - to use Thomasson's phrase - "epistemically metaphysical" (see Thomasson 2015), i.e. that they require some special method of justification which is hard to obtain. Rather, according to deflationists we need only ordinary methods of inquiry: conceptual analysis and empirical observations are enough to provide answers to questions about existence.

One important observation about the deflationary account of ontology is needed: the idea that there are certain entities/facts/properties that exist in a purely deflationary sense should not be seen as the claim that these entities/facts/properties are "minddependent" or "constructed by humans" (at least not in the strong sense). This is made clear by both Schiffer (1996) and Thomasson (2015). According to Schiffer, "pleonastic entities", such as properties or propositions, should be seen as language-independent (even though in some trivial sense they are created by language). For Thomasson, this issue is even more important: for her the paradigmatic example of deflationary entities is ordinary objects such as chairs or boulders. Although chairs are man-made in the trivial sense, ordinary objects which are not artifacts, such as rocks and so on, are not "mind-dependent" in any important sense; there is no doubt for Thomasson that such things exist in possible worlds where there are no humans.

The general deflationary schema can be quite easily transferred to the issue of the existence of beliefs. As a result, the claim that beliefs exist can easily be established. Let us use Thomasson's framework for this purpose. If we apply it to the case of beliefs, we get the following conclusion: beliefs exist if the criteria of application of the term "belief" which we accept in our folk discourse are empirically met. That this is the case can be established quite easily: it is enough to ascertain that a certain person meets the standards of being a believer that $\mathrm{p}$ (for any $\mathrm{p}$ whatsoever). Take Smith, who talks at great lengths about how Linux is superior to other operating systems, who exclusively uses Linux on his computers, who constantly nags everybody to switch to Linux, etc. We might safely say that Smith believes that Linux is the best operating system. But, in this way we have committed ourselves to the claim that there is at least one belief: namely the belief of Smith that Linux is the best operating system. So, in effect, we have shown that beliefs exist.

As has been observed, the deflationary account of the existence of certain Xs does not in itself entail that such Xs are mind-dependent. This applies to beliefs as well: applying the general deflationary ontological framework in order to establish the claim that beliefs exist does not automatically lead to the conclusion that beliefs are "constructs" of any sort. Rather, it only means that we should see their existence as a "lightweight" matter.

Additionally, it should be noted that this way of establishing this conclusion is notably similar to the way common-sense functionalists argue for the same claim: in both theories, all that is needed to prove the existence of beliefs is to reflect on the concept of belief and make some straightforward empirical observations. Commonsense functionalism might then be regarded as a sort of deflationism avant le lettre.

Some might be tempted to say that adopting such a deflationary answer to the question of the existence of beliefs provides a solution to the issue of the reality of beliefs. After all, once we accept that beliefs exist, then we should have no problem with admitting that many attributions of beliefs can and indeed are true. Some 
proponents of meta-ontological deflationism also consider any form of debate between realism and anti-realism to be misguided.

However, such quietism is not the only possible view. Many philosophers have claimed that it is perfectly possible to restate the question of realism in the deflationary framework: we might admit that certain things/entities/properties/states exist, but then we might ask whether such elements of our ontology are real. What is needed for such a project to succeed is a criterion which would allow us to distinguish between what is real and what is not fully real. Such a criterion should not be ontological in its nature, i.e. it should not lead us to the conclusion that what is deemed to be not real is nonexistent. The guiding principle of such projects is that once we make room in our ontology for many facts/entities/properties that were traditionally considered problematic, we might still retain our metaphysical scruples about them. The deflationary ontology might be extremely inclusive, but there seems to be room to distinguish a certain class of entities which we might want to relegate to the category of the not metaphysically real. What this means in detail can be spelled out in many ways, but the basic intuition is that some elements of ontology deserve to be treated as fundamental and explanatorily indispensable, whereas the existence of others might be seen as inconsequential and lightweight.

There are several examples of such philosophical projects. One of them is the program of quasi-realism in meta-ethics (see e.g. Blackburn 1993). According to quasi-realism, we might safely say that normative properties exist and normative statements can be true. However, quasi-realists want to resist a full-bloodied realist approach to normative statements; for them, normative properties are not robustly real. How this is supposed to work in detail is a subject of heated debate (see Dreier 2018 for a useful overview of the options that are available to the quasi-realist to make the real vs quasi-real distinction), but the general concept of making a distinction within the general minimalist framework is somewhat popular in contemporary meta-ethics. Fine presents a similar view: on his account (Fine 2001), the notion of grounding is used to make the distinction between the factual and the non-factual; factual propositions are those that are either fundamental or are fully grounded by factual propositions; nonfactual propositions are, on the other hand, those which contain nonfactual constituents. Perhaps the most developed account of this kind was proposed by Wright (1992), who, while adopting a generally minimalist approach to truth-aptitude, proposes several criteria which might be used to distinguish the discourses in which we use a substantial concept of truth from those in which the operative concept of truth is purely minimal.

In what follows I will not commit myself to any of the aforementioned proposals. Rather, they serve as examples to show that the idea of making a distinction between the real and the non-real in the deflationary framework is feasible (even though some of the authors quoted above do not explicitly declare themselves to deal with the issue of realism). Once we accept this possibility, then we might distinguish between two philosophical questions about beliefs: the first is the question of whether beliefs exist, which might be answered in an easy way; the other is the question of whether beliefs are real, which might be seen as being less trivial.

If we agree on the positive answer to the first ontological question, there still might be room for disagreement on how to answer the second one. In this way we get two possible views on the metaphysics of beliefs. The first view may be dubbed "minimalist 
realism", according to which beliefs exist and are real. The second is minimalist antirealism, which claims that beliefs exist but are not real. The conflict about the reality of belief is, in my view, best seen as a debate between these positions and not as a debate about the existence of beliefs.

\section{How to Be an (Anti-)Realist}

What is now needed is a criterion of reality which could be applied to the issue at hand. In my opinion the most fruitful option in the present context would be to adopt the distinction between natural and non-natural properties, as proposed by Lewis (1983). Although this distinction was not originally intended to serve as a criterion of reality, for Lewis non-natural properties had the same ontological status as natural ones, and it has subsequently been used for this purpose in some contexts which serve as an inspiration for my proposal.

An important example of a theoretical context in which this distinction was used is in the debate on deflationism about truth. In its early formulations, deflationism was presented as a view according to which there is no such property as being true (see e.g. Strawson 1950). This initial idea was quickly dismissed as it seems that irrealism about truth is an unworkable position. Thus, skepticism about the idea that there is some sort of special relation linking propositions with facts is nowadays often expressed as the claim that the property of being true is not a substantial property; in this way, the debate between proponents of deflationism and supporters of substantial theories of truth becomes a debate about what kind of property truth is. Some philosophers (see Edwards 2013) have suggested that the best way to conceptualize this distinction is by using Lewis's distinction between natural and non-natural properties. In this way deflationism becomes the claim that although we might say that there are true statements/proposition/sentences and there is such a property as being true, the property of being true is not a natural one.

It seems natural to see the debate about the status of the truth property as being roughly parallel to the debate about the reality of beliefs. In both cases the straightforward irrealist option seems to be unworkable, yet there might be space for expressing some sort of skepticism about the metaphysical reality of both the truth-relation and beliefs. So, drawing inspiration from the case of truth to the issue of beliefs should be considered a reasonable theoretical move.

Another example of adapting the Lewisian distinction to the issue of realism is Stoljar's (2014) reading of Chomsky's infamous London argument (see Chomsky 2000). A popular reading of Chomsky would see him as claiming that London does not exist; however, such a pronouncement is widely thought to be counter-intuitive. According to Stoljar, a more charitable reading of Chomsky would be to see him as claiming that for him "being a London" is not a natural property. This corresponds to other views of Chomsky, e.g. those regarding the ontological status of a desk: it would be implausible to say that there are no desks, but the claim that the property of being a desk is not a natural one has a bigger claim to plausibility. Importantly, all this relates to Chomsky's views on the status of semantically evaluable mental states. Although Chomsky is often taken to espouse eliminativism about such states, for him the metaphysical status of such states is in fact similar to that of desks: we can say that 
there are desks and that desk-eliminativism is not a viable theoretical option; we should also say that the property of being a desk will not be part of naturalistic inquiry. In the same vein, we should think of meanings and beliefs: we can admit that they exist, but we should not treat them as being worthy of being included in serious science. Thus, if we adopt Stoljar's reading of Chomsky and apply it to the issue of meaning and belief, then the natural consequence is to claim that although meaning and beliefs exist, we should not treat such properties as being natural in Lewis's sense.

In my opinion, drawing a distinction between real and non-real in this way might be theoretically fruitful in at least some contexts. I assume that the criteria of being fully real should be adopted to each specific context on a case-by-case basis (this claim does not necessarily lead to the thesis that the meaning of the word "real" is different in different context, I am only saying that the epistemic criteria might differ). In the context of beliefs, our main motivation to wonder if they are "fully real" was the question of whether they are doing genuine explanatory work and whether they constitute a category with objective boundaries. Adopting the notion of Lewisian reasonable naturalness as a criterion of the reality of beliefs seems to fit these theoretical purposes nicely.

We are now in a position to present the formulation of the realist and anti-realist positions. According to the proposed definition, a realist about beliefs is someone who claims that they exist, attributions of beliefs can be and often are true, and beliefproperties are natural in Lewis's sense. On the other hand, a minimal non-realist about belief (i.e. a specific brand of anti-realism) admits that beliefs exist and that attributions of them can be true yet claims that belief-properties are not natural in Lewis's sense.

Admittedly, such a characterization of the issue of belief realism is a revisionary one as no one has explicitly endorsed either realism or anti-realism when formulated in such a way. Nonetheless, as it has been said before, such a revision might be defended on the grounds that it makes room for theoretical advancement.

To make these definitions intelligible, the detailed characteristics of the Lewisian distinction are now needed. For Lewis (1983), properties are sets of possible objects (for example, the property of being a donkey is the set of all donkeys that exist in all possible worlds, including our world). N-place relations are sets of n-tuples of possible objects (for example, the relation of "being heavier than" is a set of all ordered pairs of possible objects, where the first object is heavier than the second etc.). Lewis distinguishes properties understood in this way from universals, which are considered genuine parts of objects; properties, on the other hand, are not present in objects. As he puts it, "far from the property being part of the donkey, it is closer to the truth to say that the donkey is part of the property" (Lewis 1983, p. 345).

Lewis is also extremely liberal in his views on properties understood as classes: for him, any set of individuals in possible worlds counts as a property. Properties understood in such a way serve as semantic values for expressions such as "redness" or "humility". Such an "abundant" conception of properties, however, cannot serve all the theoretical roles that the theories of properties should play. For this reason, Lewis distinguishes between "natural" (or "sparse") and non-natural (or "abundant") properties. "Abundant" properties are arbitrary sets of objects in possible worlds. However, among these properties there is a small, elite class of natural/sparse properties. These natural properties "carve reality at the joints" (Lewis 1983 p. 346): they ground objective similarities and the causal powers of objects. According to Lewis, we might 
either accept that natural properties are genuine universals (a view he attributes to Armstrong), or accept that there is a primitive distinction between natural and nonnatural among nominalistically acceptable properties (understood as modal classes).

It is reasonable to suspect that there will turn out to be very few such natural properties in a strict sense; in all probability, only properties which will function in fully mature fundamental physics will count as such. For this reason, Lewis introduces the notion of "reasonably natural" properties, which are those that are connected to perfectly natural properties by means of chains of definitions. This notion is graded: properties can be more or less natural in this sense. A reasonable suspicion is that such "less elite" properties will be the ones used by the special sciences.

This graded nature of the natural vs non-natural distinction is important, as many philosophically important properties are located somewhere in the middle of the spectrum. One important example might be the looping kinds ${ }^{1}$ described by Hacking (1995), i.e. human kinds which exhibit the looping effect (e.g. the "juvenile delinquent" category). The general idea is that in such cases the act of categorization using a given category changes the subjects of the classification by way of changing their self-image (among other things), therefore it changes our understanding of the world. Thus, the introduction of the category of juvenile delinquent (presumably) had certain important causal effects on the world. But are such categories natural in the Lewisian sense? In a sense the obvious answer is "no", as they would not exist without our classificatory activity; however, they seem to have some important causal import. Thus, the right thing to do would be to claim that such kinds are somewhat natural, as they fulfill the criteria of naturalness only partly.

The other important (and relatively similar) example of such in-between properties is multiply realizable properties/kinds, such as money (see e.g. Fodor 1974), which are not perfectly natural and cannot be straightforwardly reduced to fundamental physical properties; however, they still play important explanatory roles and catch some important similarities between higher-level phenomena. For this reason, they should be classified as being in the middle between perfectly natural and completely nonnatural properties.

We now need to ask whether such partly natural properties are real. If we want to define the real in terms of the notion of natural properties but it turns out that the notion of naturalness is graded, then we need to know how to classify these in-between properties. The only possible answer here is that it depends on whether the property in question is a reasonably natural one. If so, then such a property can be said to be real; in other cases - not. Reasonably natural properties are those which are not perfectly natural but can still be said to ground objective similarities, be relevant in causal explanations, and be appropriately linked to perfectly natural properties (more on these criteria below). In each case of a human kind or a multiply realizable property, we must decide whether it fits the criteria of reasonable naturalness and whether it should be deemed real.

In relation to the issue of beliefs, there is little tendency to suppose that beliefproperties would be perfectly natural in the aforementioned sense: no one expects that future fundamental science will have any use for any higher-level mental properties. Thus, the issue of the naturalness of belief-properties is the issue of whether they can be

\footnotetext{
${ }^{1}$ I'm grateful to an anonymous reviewer for drawing my attention to this point.
} 
seen as reasonably natural (as opposed to both completely non-natural and perfectly natural). This issue can be translated into three more specific questions: first, whether belief-properties ground objective similarities; second, whether they are relevant in causal explanations; third, whether they are connected via definitional chains to more fundamental, perfectly natural properties. In all these cases, the realist is committed to giving positive answers, whereas the anti-realist is committed to negative ones. The criteria of naturalness of properties that are adopted here can, as I will presently show, be connected with important issues debated within contemporary metaphysics of belief.

The first criterion is that of objective similarity. If belief-properties were reasonably natural, then we could treat objects that share such properties as being objectively similar. This claim could be understood in two ways. First, it could be said that attributions of beliefs with particular content are to be seen as depicting objective similarities between subjects who hold the belief in question. For example, are two persons who believe that Paris is the biggest city in the European Union objectively similar to each other in virtue of harboring this particular belief? Second, this question might refer to belief understood as a category: does the category of belief carve out a set of mental states which are objectively similar to each other?

The first issue is the question of whether individuation of mental states such as beliefs on the basis of their content might be seen as providing us with objective results. This was famously problematized by Stich (1983), who pointed out that in our folk psychological practice we categorize beliefs on the basis of their content, but this practice is heavily context dependent. To prove this point, Stich introduces the famous example of Mrs. T, who harbors the belief that McKinley was assassinated; however, Mrs. T suffers from a disease which results in gradual loss of memory, and, as a result, she loses the beliefs "surrounding" this particular one: she forgets who McKinley was or what it means to be assassinated. So the question might arise: does Mrs. T have the belief that McKinley was assassinated? On Stich's view there is no "right" answer to such a question, which for him is a strong argument to deny the reality of beliefs. On the opposite side of the spectrum, the proponents of the representational theory of mind (on which more below) would be committed to the idea that having beliefs with the same content is a matter of sharing a certain internal representation of some sort; in this way attributions of beliefs with particular content would track some objective similarity.

The other issue is the question of whether the category of belief is an objective one. In our folk psychological practice, we divide the mental states which we attribute to ourselves and others into several distinct categories: some states we classify as beliefs, others as imaginations, delusions, etc. The question that arises with respect to this classificatory practice is the following: are these distinctions objective? Does the category of "belief" have objective boundaries?

This question points us directly to the problem of whether beliefs constitute a natural kind. This is a part of the broader issue of the status of psychological kinds: many philosophers have wondered whether we can treat kinds of folk psychology and psychiatry as natural (see, e.g., Cooper 2013 for the issue of whether emotions are natural kinds; see Griffiths 2004 for the status of emotions as a kind). It seems that most theorists reject the idea that psychological kinds are natural in the strong sense (i.e. that they have hidden "micro essences"). However, the possibility that they could be seen as natural kinds in a weaker sense (namely as kinds which serve as a basis for inductive 
generalizations; such weaker conception of natural kinds have been developed by such philosophers as Boyd (1991) and Khalidi (2013)) is still treated as open.

Thus, the question of whether beliefs form natural kinds translates into the question of whether there are robust empirical generalizations about this category. Obviously, the answers provided by realists and anti-realists would differ here: Quilty-Dunn and Mandelbaum (2018) contend that there are such generalizations, whereas Jenson (2016) (who adheres to eliminativism) claims that there are none. A notable (and interesting from the point of view of mild anti-realism) alternative to the view that beliefs form a natural kind is the idea that they constitute a human kind, as was proposed by Dewhurst (2017).

Another important context in which the issue of whether beliefs are natural kinds and whether attributions of them point to objective similarities arises is the issue of discrepancy between professed opinions and beliefs: there are many familiar cases that are widely discussed in philosophical literature (see e.g. Gendler 2008; Tumulty 2014) and in which the subject's behavior is not in accordance with their professed opinions. One of the most discussed examples is the famous skywalk case: a person who designed a skywalk is ready, after making all the relevant calculations, to sincerely profess that the skywalk is safe to walk on. However, when presented with the opportunity to walk on it herself, she is hesitant to do so. The question that arises is whether this person truly believes that the skywalk is safe. In general, in cases of discrepancy the problem is whether we should attribute beliefs to people on the basis of their sincere assertions, even in the light of their discordant behavior.

Several answers are proposed in this context (see Tumulty 2014 for an overview), but from our perspective the most important observation is that the debate surrounding this issue has led to a meta-philosophical question (see Bayne and Hattiangadi 2013): does the question of whether a certain mental state should be classified as a belief have a correct answer? In other words: does the category of belief have objective boundaries? A positive answer to this question would render beliefs as constituting a natural kind, whereas a negative one would mean that this category is to a large extent arbitrary. Naturally, someone who regards beliefs as being part of the deep reality of human cognition would go for the option that there are natural boundaries of this category that separate beliefs from other kinds of mental states. The sceptics would rather be tempted to see this category as being more or less "constructed" (this way of seeing the problem is inspired by Matthews 2013). Such a constructivist view corresponds nicely with mild anti-realism and with the denial of the claim that beliefs constitute a natural kind.

The second criterion of the naturalness of a property is that of relevance in causal explanation. This criterion straightforwardly translates into one of the major issues in the contemporary metaphysics of beliefs (and mental states in general), namely the problem of causal exclusion. As presented in a classic way by Malcolm (1968) and developed and popularized by Kim $(1998,2005)$, the causal exclusion argument aims to show that it is impossible to account for the phenomenon of mental causation in the frameworks of property dualism and non-reductive physicalism. I will not restate the well-known argumentative strategy here (a useful overview can be found in Kallestrup 2006).

Instead, I want to focus here on the relation of the problem of causal exclusion to the issue of realism. Kim explicitly states that the failure to resolve the problem of causal 
exclusion would have disastrous effects. If it turned out that we would be forced to deny that mental states are genuinely causally efficacious (i.e. we would have to embrace epiphenomenalism), we would consequently be forced to accept eliminativism. For Kim, mental states which do not play a genuine causal role could also be removed from our ontology.

It might be debated whether epiphenomenalism must lead to straightforward eliminativism, but it is certainly true that the strongly realist position about beliefs is indeed committed to their causal efficacy. As Fodor puts it: "someone is a Realist about propositional attitudes iff (a) he holds that there are mental states whose occurrences and interactions cause behavior and do so, moreover, in ways that respect (at least to an approximation) the generalizations of common-sense belief/desire psychology; and (b) he holds that these same causally efficacious mental states are also semantically evaluable" (Fodor 1985, p. 78). Thus, it is reasonable to say that the issue of causal efficacy might indeed be used to distinguish between strong realism and mild forms of anti-realism with regard to beliefs.

It is vital to note in this context that at least three notions are pertinent here: the first is the notion of metaphysically fundamental causation; the second is the notion of relevance in causal explanations; the third is the notion of relevance in any sort of scientific explanation. The difference between metaphysically fundamental causation and causal relevance (or counterfactual causation) is often stressed in discussion of the problem of causal exclusion: many philosophers (see e.g. Bennett 2008) claim that it would be unreasonable to suppose that beliefs, qua higher-level phenomena, can be causally active in the fundamental sense of causation. This is because it might easily turn out that only fundamental physical properties/entities/events could play this role, therefore beliefs would trivially turn out to be causally inactive in this sense. On the other hand, the notion of relevance in any sort of scientific explanation is a very liberal one, and beliefs certainly do play some sort of explanatory role in some sciences (e.g. historians routinely explain what certain people did by resorting to their beliefs). Thus, causal relevance seems to be best suited to playing the role of a criterion of reality (at least in case of beliefs), as the question of whether beliefs play an indispensable role in causal explanations seems to be non-trivial.

The third criterion which allows us to decide whether a given property is reasonably natural is the relation of belief-properties to more natural/fundamental properties. On the intuitive level, there is some appeal to the notion that if a given property which itself is not fundamentally real is to be said to be real, then it should be appropriately connected to truly fundamental properties. In Lewis's original formulation, this connection was thought to be a definitional ${ }^{2}$ one: reasonably natural properties should be definable in terms of perfectly natural ones. This formulation might be considered controversial, but I think a more relaxed notion of explanatory links might be of use here: what we require of reasonably natural properties is that there are some intelligible explanatory links between them and fundamental properties. For example, although one might be skeptical of whether it is possible to define higher-level, multiply realizable properties such as money in terms of fundamental properties, one might expect that such properties could be somehow be explained by their relation to some more fundamental properties (we might expect, for example, that money can be

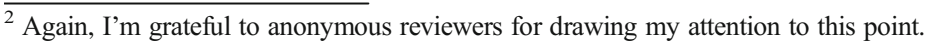


explained in terms of economic preferences and so on). This postulate can be easily applied to the case of beliefs: if they are real, then there should be some explanatory connection between them and more fundamental properties.

Beliefs are usually understood as having two aspects: that of being internal states responsible for behavior, and that of being bearers of semantic content. The first aspect seems to be quite unproblematic from the point of view of providing an explanatory link to some more fundamental properties. What seems unclear, however, is how the second aspect, namely the putative fact that beliefs have content, can be explained in terms of more fundamental properties. This problem is closely related to an important debate in the metaphysics of beliefs, namely the problem of naturalization of content.

The question of naturalization of content is the question of how we can explain in a naturalistically acceptable way the fact that beliefs (and other propositional attitudes) have representational, propositional content. The problem is the following: if we admit that mind is a natural phenomenon which is governed by the same laws of nature as everything else, then how might it be "about something"? This problem becomes especially dramatic in the content of beliefs: beliefs are not only "about something" in the sense of object-directness, but they possess truth-conditions, which means that they are capable of representing possible states of affairs. But explaining in a naturalistically acceptable way how anything can represent possible states of affairs is not an easy task. Again, it is not my aim here to provide a summary of the proposals that have been put forward in order to do this, as the debates concerting these proposals are extremely intricate. What I want to focus on is the connection between this problem and the issue of belief-realism.

As Shea has noted, "a naturalistic account of mental content must provide illuminating explanatory connections between representational content and properties that are non-semantic, non-mental and non-normative" (Shea 2013, p. 497). This formulation allows us to see the connection between the issue of naturalization of content and the issue of belief-properties being natural (or non-natural); as it turns out, the question of naturalization of content is the question of whether there are appropriate definitional links between attribution of content and more fundamental naturalistic descriptions. This, in turn, is commonly thought to have serious implications for the question of realism about beliefs (and other intentional states). A good example might be the position of Rosenberg $(2013$, 2015), who motivates his eliminativist stance towards belief by a negative appraisal of the prospect of naturalization of content. On the other side of the debate, Shea (2013) might serve as an example of a philosopher for whom the success of the project of the naturalization of content is a prerequisite of realism about mental states.

An alternative account of how to link beliefs and their content to more natural properties is the view according to which intentional states should be explained not in naturalistic terms but in relation to the notion of phenomenal consciousness (see Mendelovici and Bourget 2014 for a useful overview of this position). This proposal is as intricate as it is controversial, and for this reason the detailed analysis of it must be postponed for another occasion. What is important here is that even on this view the reality of intentional properties of beliefs seems to hinge on their relation to something which is considered to be more metaphysically fundamental. For the purposes of the present paper, I will ignore this option and, for the sake of simplicity, treat the naturalization of content as a criterion of realism (but with full knowledge that the 
project of phenomenal intentionality, if successful, could also provide a basis for realism).

\subsection{Paradigmatic Positions}

We are now in a position to present the paradigmatic versions of realism and antirealism in the proposed framework. Paradigmatic realism about beliefs might be defined as a conjunction of three claims:

1. Beliefs constitute a cognitive natural kind with objective boundaries, and attributions of beliefs with particular content track objective similarities.

2. Beliefs play a genuine causal explanatory role.

3. It is possible to provide a naturalistic account of content.

Paradigmatic anti-realism (which I call "minimal non-realism") would consist of negations of these claims, so it would consist of the conjunction of the following claims:

1. The category of "belief" is (to a significant extent) an arbitrary one, and no objective similarities are tracked by attribution of beliefs with particular content.

2. Beliefs are not indispensable in causal explanations.

3. There is no interesting story about naturalization of content.

Two things need to be noticed about the proposed distinction. First, strong realism and minimal non-realism, characterized as above, are definitely ideal-type positions: i.e. they are theoretical posits which aim to illuminate the debate. Real-life views on the metaphysics of beliefs might only approximately match the idealized descriptions. Second, this distinction has a spectrum-like character in the sense that is commonly used in psychological diagnostics: there are several linked yet in principle detachable criteria which we can use to assign a given case to a certain category; moreover, each of these individual criteria is more or less vague.

In my view, such a spectrum approach is the right one as the opposition between the realistic and anti-realistic approaches to beliefs is not binary. The binary character was suggested by the "Quinean" conceptualization of the distinction in question, according to which you either accepted that beliefs existed or not. In my view, things are more complicated. One might partially accept the intuitions that lie behind the ideal-type realist or non-realist positions: for example, one might think that there is some way of naturalizing content but be skeptical about mental causation, etc.

Let us now turn to the question of how the proposed definitions relate to real positions in metaphysics of belief. An actual example of a theory that comes somewhat close to my characterization of a strongly realist position is psychofunctionalism, which was recently defended by Quilty-Dunn and Mandelbaum (2018), according to whom we should define the concept of belief by the laws of scientific psychology in which this concept functions. According to Quilty-Dunn and Mandelbaum, such an approach would result in adopting some version of a representationalist theory of beliefs, according to which we should treat beliefs as real states that are somehow stored in the brain, enter genuine causal relations, and have semantic properties. 
When it comes to examples of minimal, "soft", anti-realist views, there are several views on the metaphysics of belief that more or less fit the proposed definition. One of them is Chomsky's version of eliminativism. As was already noted before, for Chomsky (2000) the ontological status of beliefs is akin to the ontological status of desks and the like: for him beliefs and other intentional states should be eliminated from the scientific account of human cognition, yet this does not mean that we should eliminate such notions from our everyday speech (see also Collins 2007 for an overview of Chomsky's version of eliminativism).

Other cases of views on beliefs which might be thought of as being similar to the proposed minimal non-realist view are Davidson's anomalous monism and Schwitzgebel's neo-behaviorism. In Davidson's view (Davidson 1970), the world consists of events: all events are physical as they can be described using physical laws, but some of them are also mental events as they can be described using the mental idiom. Davidson's core claim is that even though all events are physical the language of psychology remains autonomous as there are no psycho-physical laws. The anti-realist element of this theory consists, in my opinion, of two claims. First, for Davidson, being a mental event (for example a belief) is just a matter of falling under an appropriate description. As Davidson himself admits, the mental for him is "is not an ontological but a conceptual category" (Davidson 2004, p. 114). Secondly, Davidson explicitly denies that mental events (including beliefs) play a causal role "in virtue of" having mental properties (Davidson 1992); this makes Davidson vulnerable to the charge of type-epiphenomenalism (Kim 1998). Obviously, Davidson would not accept the general framework that I propose here: as a convinced nominalist, he would be skeptical of the idea that we might distinguish the real from the not real by way of the distinction between natural and non-natural properties. Still, there was an important anti-realist bent in Davidson's outlook on beliefs which justifies treating his views as somehow parallel to anti-realism as defined here.

Davidson is often classified as a belonging to the broader tradition of interpretivism, which was also developed by Dennett (1987) and more recently by Mölder (2010). The basic idea of interpretivism is that we should not see beliefs as concrete internal states. Rather, we should see the truth of belief-ascriptions as stemming from the fact that application of the intentional stance to a given system yields good predictions. In this way, interpretivism avoids commitment to any strong realism about beliefs but retains the claim that belief attributions can be true.

Mölder's version of interpretivism is especially important in the context of the proposal developed here, as he explicitly uses the Schifferian notion of pleonastic properties in his analysis of beliefs. Thus, his position serves as an important source of inspiration for minimal non-realism for two reasons. First, Mölder accepts a broadly deflationary meta-ontological framework as the proper basis for discussion of the problems of philosophy of mind. Second, he sees the need to introduce some sort of distinction between the strongly real and less real in this deflationary framework: he emphatically distinguishes between "pleonastic" and "natural" properties, and for him belief-properties fall into the former category.

Despite these affinities, there is also an important difference between the interpretivist view and minimal non-realism as it was defined in the present paper: most interpretivists seem to accept the idea that beliefs are somehow constituted by the process of interpretation and ascription. I find this view problematic: the idea that 
beliefs metaphysically depend on the process of their ascription leads, in my view, to serious concerns about the epistemology of mental states and about the circularity of the interpretivist theory. I have elaborated on these points elsewhere (Poslajko 2020). What needs to be stressed here is the fact (which was noted in section 2) that minimal non-realism, as presented here, does not imply the claim that beliefs are minddependent in any strong sense.

The next view worth mentioning here is Schwitzgebel's neo-behaviorism. Its main tenet is the claim that having a belief is a matter of fitting a certain dispositional stereotype (Schwitzgebel 2002). In my opinion, the "anti-realist" element in Schwitzgebel's approach lies in the fact that for him the category of belief does not have objective boundaries: in some cases there is no right answer to the question of whether a certain mental state should be classified as being a "belief" (Schwitzgebel 2010). This is because questions about the similarity of a certain person to the behavioral stereotype of the believer that $\mathrm{p}$ can lack objective answers. Moreover, Schwitzgebel is opposed to any form of strong realism of the representationalist variety, as for him the category of belief is a superficial one: attributions of beliefs rely on publicly available criteria and not on presuppositions about deep cognitive structures (Schwitzgebel 2013). It needs to be noted, however, that Schwitzgebel would probably not adopt the "anti-realism" label to his position.

As the aforementioned positions are not full realizations of the minimal anti-realist position, it might be useful to say something more on how the ideal-type proponent of minimal non-realism would see the status of belief-talk. According to this view, attributions of beliefs are capable of having truth value and often are indeed true. However, the fact that such attributions can be true does not mean that they track any objectively similar cognitive structures; additionally, such attributions might be considered dispensable in a mature science of human cognition.

Let us consider a stock example of belief attribution and imagine two persons of whom it is true that they believe that John F Kennedy went to Harvard. In the case of such persons, we might say that there is something that somehow makes this attribution true: there is some combination of subpersonal cognitive events, behavioral dispositions (both verbal and non-verbal), and (perhaps) some introspectively available internal phenomenological states. In this way, these subjects might meet the folkpsychological criteria of attribution of belief with this content.

According to the anti-realist, despite the fact that two given subjects can be truly said to harbor the belief in question, they can be very dissimilar with regard to their psychological constitution. For example, one of these persons might be a scholar in US politics who is keenly interested in Kennedy's biography and has been to Harvard personally, etc. The other might be a disinterested student who half read a page from a history textbook about Kennedy and remembered that "Kennedy went to Harvard" but does not have much relevant information about the matter except that "Kennedy is some sort of politician of the old days" and that "Harvard is some fancy school". On each level of psychological description, there might serious differences between these two subjects: there might be big differences between their subpersonal cognitive structures (think of the differences in their declarative memory), their verbal and nonverbal dispositions might radically differ (the scholar might be more than willing to engage in a long conversation about the subject etc.), and their phenomenology might also differ (it seems reasonable to assume that the scholar would have far more vivid 
"impressions" when confronted with these statements). There might be some similarities, but in the view of a minimal non-realist these possible similarities would not cut deep.

\section{Advantages of the Proposal}

I think that framing the distinction in the proposed way has several important advantages. First, it allows us to formulate the anti-realist view in a coherent way that makes the debate non-trivial. The traditional form of anti-realism, namely eliminativism, was regarded as extremely counter-intuitive (at best) and outright incoherent at worst. But this conclusion has disastrous consequences for the status of the debate: if we are unable to formulate an alternative to realism about beliefs which has at least some claim to plausibility, then the issue will become philosophically irrelevant. The worry is that the issue of belief realism will become trivial. This, paradoxically, might also be seen as bad news for the "winning" side: realism about beliefs (understood simply as the claim that beliefs exist) becomes an uninteresting claim.

The version of anti-realism that is defined in this paper is neither obviously selfdefeating nor terribly counter-intuitive. The standard arguments from self-contradiction do not seem to apply to the view in question. The proponents of minimal non-realism do not deny that we can truly attribute beliefs to other people and ourselves. In this way, they can safely self-attribute the belief in the truth of the position in question: they can say of themselves that they believe that beliefs are not natural properties - that the attribution of beliefs does not track objective similarities, etc. As was noted above, the main reason why the original eliminativist position was regarded as self-contradictory was the inability of eliminativists to self-attribute belief in their own position. However, as minimal non-realism does not share this problem, the standard versions of the cognitive suicide argument do not seem to be efficient against this position.

Of course, there might be more subtle arguments whose aim is to show that an antirealist view about beliefs based on the minimalist approach to existence (and truth) is, in fact, inconsistent (an interesting example of such an argument can be found in Wright (2002)). Such arguments would certainly require critical engagement on the part of proponents of minimal non-realism. Importantly, however, the existence of such subtle arguments does not mean that minimal non-realism is a non-starter: subtle arguments to prove that a certain position is inconsistent are commonplace in philosophy. What is crucial is that minimal non-realism is not obviously inconsistent, and this is enough to make this view at least worthy of consideration.

When it comes to the relation of the proposed view to common sense, it might be said that minimal non-realism is a position which is in conflict with some commonly held convictions about beliefs. It seems reasonable to suppose that part of the folk conception of belief is the idea that beliefs are genuine causes of behavior. If the moderate anti-realists about beliefs deny this, then they might part way with common sense. Still, this is not something that must be taken as a fatal flaw: there are numerous theories on the philosophical marketplace of ideas that seem to fly in the face of some aspects of common sense (think of theories of personal identity, for example); however, unless such conflict is intolerable, these theories should not be automatically disqualified. 
The second advantage of the proposed conceptualization is that it allows the distinction between realism and anti-realism in the area of beliefs to be made tractable, at least up to a point. The problem with the traditional formulation of eliminative materialism was that it was not clear how we should decide whether beliefs exist. This point was forcefully made by Stich (1996), who complained that the question of the existence of beliefs hinges on hard questions about the reference of the term "belief" and the equally complex issues of inter-theoretic reduction.

The formulation of the problem of the reality of beliefs in terms of natural vs nonnatural properties offers the prospect of making at least some progress in this respect. As the question "are beliefs real?" can be divided into three more specific questions, the idea is that by making strides in these more specific areas we can shed light on the general question. Admittedly, none of these specific questions is really straightforward; however, the proposed conceptualization offers at least some way of getting the debate about the reality of beliefs off the ground.

The third advantage of the proposed account is that it allows some theoretical unity to be introduced into various debates in the contemporary metaphysics of beliefs. All the debates I have pointed to, namely the discussions about the status of belief as a natural kind, about the causal efficacy of beliefs, and about the naturalization of content, have in their background the assumption that their result would somehow be important for the question of the reality of beliefs. However, these debates are largely disconnected from each other, and their relation to the general issue of realism about beliefs is rarely explained. The proposal I offer here allows one to see how these issues might be treated as being parts of bigger story. Although the answers to these issues are logically independent of each other, all of them are interconnected in this sense: providing an answer to each of them contributes to the general outlook on the metaphysical status of beliefs. Thus, by combining the answers to these separate issues, we might be able to obtain a unified view on the metaphysical status of beliefs.

\section{Tentative Reasons to Prefer Minimal Non-realism}

Each of the questions that that count as partial criteria of belief realism, as defined in this paper, have a long and complex history; there have been numerous theoretical proposals with regard to these issues, and each of these proposals sparked intricate philosophical debate. For this reason it would be impossible to fully engage in any of these problems here; however, I think that it is possible to provide at least some broadbrush, general considerations which could speak in favor of adopting a general preference towards the anti-realist view.

In all of the cases, it is the proponent of the realist view that puts forwards claims which carry a significant theoretical and evidential burden. To claim that beliefs constitute natural kind, that they are causally active, and that there is a way to provide a naturalistic analysis of content is to make substantial commitments about the structure of human cognition, and in each case these commitments have been subject to serious criticism.

Obviously, each of the issues in question would require much more serious attention than can be offered here. Still, I think that it is important to note that in every case there are important voices that support the skeptical hypotheses. One example of such 
skeptical arguments might be Rosenberg's (2015) criticism of the idea that we might use the framework of evolutionary biology to provide a naturalistic analysis of propositional content. Similar reasons for skepticism can also be found in other cases. The mere existence of arguments which aim to show that anti-realism is the right view does not prove that it is in fact correct. However, my point here is not that we have once-andfor-all proofs of the particular claims that constitute minimal non-realism about belief; rather, my point is that in each case there are at least some tentative reasons for the antirealist view.

I am convinced that the question of realism about beliefs is an epistemically open one: the current state of evidence does not allow one to say with absolute certainty that either option is fundamentally right. However, in a situation in which we lack the final answers, opting for the one which is, as it were, more metaphysically conservative and philosophically cautious can be seen as a reasonable choice. Minimal non-realism about beliefs postulates that there is less structure in our cognitive lives than many philosophers have suspected as it claims that attribution of certain mental properties does not track deep/substantial cognitive facts. In this way the anti-realist view is more theoretically modest and parsimonious then the realist one. Obviously, not everybody would be convinced by such an appeal to parsimony and theoretical caution, but my aim here is just to show that it is not unreasonable to adopt the anti-realist view, and there are important theoretical virtues that might be invoked to defend this view.

\section{Conclusion}

The traditional formulation of metaphysical skepticism towards the idea that people really do have internal, causally active, semantically evaluable states such as beliefs took the form of the claim that there are no beliefs. This formulation proved unfortunate, and the whole debate started to look meaningless. But the core intuition behind eliminative materialism about beliefs - that there might be something deeply wrong about the claim that we indeed have such states and that the actual architecture of the human mind might be very unlike what we take it to be on the pre-theoretical level might be formulated in a way that does not lead to an obvious inconsistency and an incredulous stare.

In the present paper I have proposed an attempt at such a reformulation by adopting the Lewisian distinction between natural and non-natural properties. It is my conviction that this way of rephrasing the positions in the debate is the most theoretically fruitful. But even if some readers find this formulation unconvincing, my other hope is that it has at least managed to convey the idea that the metaphysical status of beliefs is something that needs to be subject to serious philosophical debate.

An obvious question that arises here is whether the proposed conceptualization generalizes to other folk-psychological notions. Can we ask about the reality of other folk-psychological categories by asking whether they denote natural properties? It would be tempting to say that this is the right thing to do, but some caution might be required: the formulation I proposed here relies, at least in part, on the idea that beliefs are conceptualized as content-bearing states, and this characteristic might be less 
important in the case of other folk-psychological categories. The issue of how to best see the issue of realism in folk psychology in general definitely requires further attention.

Acknowledgments The paper was presented at the Fifth Philosophy of Language and Mind Network Conference in St Andrews, and at the Polish Semiotic Society meeting in Warsaw. I am grateful to Joanna Komorowska-Mach, Tadeusz Ciecierski, Witold Hensel, Maja Spener, Max Kölbel, Katalin Farkas, Chris Gauker, JP Grodniewicz, Anna Drożdżowicz, Pawel Banaś, Brice Bantegnie, Peter Pagin, and anonymous reviewers at Review of Philosophy and Psychology for their helpful comments.

Funding This publication was financed by the Polish National Agency for Academic Exchange under Grant No. PPI/APM/2018/1/00022.

Data Availability Not applicable.

Code Availability Not applicable.

\section{Declarations}

\section{Conflicts of Interest/Competing Interests Not applicable.}

Open Access This article is licensed under a Creative Commons Attribution 4.0 International License, which permits use, sharing, adaptation, distribution and reproduction in any medium or format, as long as you give appropriate credit to the original author(s) and the source, provide a link to the Creative Commons licence, and indicate if changes were made. The images or other third party material in this article are included in the article's Creative Commons licence, unless indicated otherwise in a credit line to the material. If material is not included in the article's Creative Commons licence and your intended use is not permitted by statutory regulation or exceeds the permitted use, you will need to obtain permission directly from the copyright holder. To view a copy of this licence, visit http://creativecommons.org/licenses/by/4.0/.

\section{References}

Baker, Lynn Rudd. 1987. Saving Belief. Princeton University Press.

Bayne, Tim, and Anandi Hattiangadi. 2013. Belief and its bedfellows. In New essays on belief, ed. Nikolaj Nottelmann, 124-144. Palgrave Macmillan.

Bennett, Karen. 2008. Exclusion again. In Being reduced: New essays on reduction, explanation, and causation. Ed. J. Howhy, J. Kallestrup, 280-305. Oxford University Press.

Blackburn, Simon. 1993. Essays in Quasi-Realism. Oxford University Press.

Boghossian, Paul A. 1990. The status of content. The Philosophical Review 99 (2): 157-184.

Boyd, Richard. 1991. Realism, anti-foundationalism and the enthusiasm for natural kinds. Philosophical Studies 61 (1): 127-148.

Chomsky, Noam. 2000. New horizons in the study of language and mind. Cambridge University Press.

Churchland, Paul M. 1981. Eliminative materialism and propositional attitudes. The Journal of Philosophy 78 (2): 67-90.

Churchland, Paul M. 2007. The evolving fortunes of eliminative materialism. In Contemporary debates in philosophy of mind, ed. Brian P. McLaughlin and Jonathan D. Cohen, 160-182. Blackwell.

Collins, John. 2007. Meta-scientific eliminativism: A reconsideration of Chomsky's review of Skinner's verbal behavior. The British Journal for the Philosophy of Science 58 (4): 625-658. 
Cooper, Rachel. 2013. Natural kinds. In Oxford handbook of philosophy and psychiatry, ed. K.W.M. Fulford, M. Davies, R. Gipps, G. Graham, J. Sadler, G. Stanghellini, and T. Thornton, 950-965. Oxford University Press.

Daly, Chris. 2013. Psychology and indispensability. The Monist 96 (4): 561-581.

Davidson, Donald. 1970. Mental events. Experience and theory 44: 43-64.

Davidson, Donald. 1992. Thinking causes. In Mental Causation, ed. John Heil and Alfred R. Mele, 3-17. Oxford University Press.

Davidson, Donald. 2004. Problems in the explanation of action. In Problems of rationality, 101-116. Oxford University Press.

Dennett, Daniel C. 1987. The intentional stance. MIT Press.

Dennett, Daniel C. 1991. Real patterns. The Journal of Philosophy 88 (1): 27-51.

Dewhurst, J.E. 2017. From folk psychology to cognitive ontology. Dissertation, University of Edinburgh.

Dreier, Jamie. 2018. The real and the quasi-real: Problems of distinction. Canadian Journal of Philosophy 48 (3-4): 532-547.

Edwards, Douglas. 2013. Truth as a substantive property. Australasian Journal of Philosophy 91 (2): 279294.

Fine, Kit. 2001. The question of realism. Philosophers' Imprint 1: 1-30.

Fodor, Jerry. 1974. Special sciences (or: The disunity of science as a working hypothesis). Synthese 28: 97115.

Fodor, Jerry. 1985. Fodor's guide to mental representations. Mind 94: 76-100.

Fodor, Jerry. 1987. Psychosemantics: The problem of meaning in the philosophy of mind. Vol. 2. MIT press. Gendler, Tamar. 2008. Alief and Belief. The Journal of Philosophy 105 (10): 634-663.

Griffiths, Paul E. 2004. Emotions as natural and normative kinds. Philosophy of Science 71 (5): 01-911.

Hacking, Ian. 1995. The looping effects of human kinds. In Causal cognition: A multidisciplinary debate, ed. D. Sperber, D. Premack, and A. Premack, 35-94. Oxford: Clarendon Press.

Jackson, Frank, and Philip Pettit. 1990. In defence of folk psychology. Philosophical Studies 59 (1): 31-54.

Jackson, Frank, and Philip Pettit. 1993. Folk belief and commonplace belief. Mind and Language 8 (2): 298305.

Jenson, J. Christopher. 2016. The belief illusion. The British Journal for the Philosophy of Science 67 (4): 965-995.

Kallestrup, Jesper. 2006. The causal exclusion argument. Philosophical Studies 131 (2): 459-485.

Khalidi, Muhammad Ali. 2013. Natural categories and human kinds: Classification in the natural and social sciences. Cambridge: Cambridge University Press.

Kim, Jaegwon. 1998. Mind in a physical world: An essay on the mind-body problem and mental causation. MIT press.

Kim, Jaegwon. 2005. Physicalism, or something near enough. Princeton University Press.

Lewis, David. 1983. New work for a theory of universals. Australasian Journal of Philosophy 61 (4): $343-$ 377.

Malcolm, Norman. 1968. The conceivability of mechanism. The Philosophical Review 77: 45-72.

Mallon, Ron, Euduard Machery, Shaun Nichols, and Stephen Stich. 2009. Against arguments from reference. Philosophy and Phenomenological Research 79 (2): 332-356.

Matthews, Robert J. 2013. Belief and belief's penumbra. In New essays on belief, ed. Nikolaj Nottelmann, 100-123. Palgrave Macmillan.

Mendelovici, Angela, and David Bourget. 2014. Naturalizing intentionality: Tracking theories versus phenomenal intentionality theories. Philosophy Compass 9 (5): 325-337.

Mölder, Bruno. 2010. Mind ascribed. An elaboration and defence of interpretivism. John Benjamins.

Poslajko, Krzysztof. 2020. Can Deflationism save Interpretivism? Philosophia 48 (2): 709-725.

Quilty-Dunn, Jake, and Eric Mandelbaum. 2018. Against dispositionalism: Belief in cognitive science. Philosophical Studies 175 (9): 2353-2372.

Quine, Willard V. 1948. On what there is. The Review of Metaphysics 2 (1): 21-38.

Quine, Willard V. 1960. Word and object. MIT Press.

Ravenscroft, I. 2016. Folk psychology as a theory. In The Stanford Encyclopedia of Philosophy (Fall 2016 Edition). Ed. Ed Zalta. http://plato.stanford.edu/entries/folkpsych-theory/. Accessed 10 June 2020.

Rosenberg, Alex. 2013. How Jerry Fodor slid down the slippery slope to anti-Darwinism, and how we can avoid the same fate. European Journal for Philosophy of Science 3 (1): 1-17.

Rosenberg, Alex. 2015. The genealogy of content or the future of an illusion. Philosophia 43 (3): 537-547.

Rupert, Robert D. 2018. Representation and mental representation. Philosophical Explorations 21 (2): 204 225 . 
Schiffer, Stephen. 1996. Language-created language-independent entities. Philosophical Topics 24 (1): 149167.

Schwitzgebel, Eric. 2002. A phenomenal, dispositional account of belief. Nô̂s 36 (2): 249-275.

Schwitzgebel, Eric. 2010. Acting contrary to our professed beliefs or the gulf between occurrent judgment and dispositional belief. Pacific Philosophical Quarterly 91 (4): 531-553.

Schwitzgebel, Eric. 2013. A dispositional approach to attitudes: Thinking outside of the belief box. In New essays on belief, ed. Nikolaj Nottelmann, 75-99. London: Palgrave Macmillan.

Shea, Nicholas. 2013. Naturalising representational content. Philosophy Compass 8 (5): 496-509.

Stich, Stephen P. 1983. From folk psychology to cognitive science: The case against belief. MIT press.

Stich, Stephen P. 1996. Deconstructing the mind. Oxford University Press.

Stoljar, Daniel. 2014. Chomsky, London and Lewis. Analysis 75 (1): 16-22.

Strawson, Peter F. 1950. Truth. Journal of Symbolic Logic 15 (3): 215-215.

Thomasson, Amie. 2015. Ontology made easy. Oxford University Press.

Tumulty, Maura. 2014. Managing mismatch between belief and behavior. Pacific Philosophical Quarterly 95 : 261-292.

Wright, Crispin. 1992. Truth and objectivity. Harvard University Press.

Wright, Crispin. 2002. What could antirealism about ordinary psychology possibly be? The Philosophical Review 111 (2): 205-233.

Zawidzki, Tadeusz. 2013. Mindshaping: A new framework for understanding human social cognition. MIT Press.

Publisher's Note Springer Nature remains neutral with regard to jurisdictional claims in published maps and institutional affiliations. 